\title{
POLICY SIGNALING IN THE OPEN ECONOMY: A RE-EXAMINATION
}

\author{
Allan Drazen \\ Working Paper 5892 \\ NATIONAL BUREAU OF ECONOMIC RESEARCH \\ 1050 Massachusetts Avenue \\ Cambridge, MA 02138 \\ January 1997
}

This paper was prepared for the Eleventh World Congress of the International Economics Association, held in Tunis, Tunisia, December 17-22, 1995. I wish to thank Steve Barnett for excellent research assistance. Leonardo Bartolini and Paul Masson, my co-authors on some of the work discussed in this paper, deserve a good deal of credit for a number of the points that are made. Errors and omissions are my responsibility. This paper is part of NBER's research programs in Economic Fluctuations and Growth and International Finance and Macroeconomics. Any opinions expressed are those of the author and not those of the National Bureau of Economic Research

(C) 1997 by Allan Drazen. All rights reserved. Short sections of text, not to exceed two paragraphs, may be quoted without explicit permission provided that full credit, including $(\mathcal{C}$ notice, is given to the source. 
Policy Signaling in the Open Economy:

A Re-examination

Allan Drazen

NBER Working Paper No. 5892

January 1997

JEL Nos. F41, E60

Economic Fluctuations and Growth

and International Finance and Macroeconomics

\title{
ABSTRACT
}

The standard model of signaling used in open economy macroeconomics concentrates on building a reputation when a policymaker's "type" is unknown. Observing tough policy leads market participants to raise the probability that a policymaker is tough, and therefore to expect tough policy in the future. This approach leaves unexplained a number of commonly observed occurrences, for example, toughness in defending an exchange rate leading to increased speculation against the currency. To explain many phenomena, this paper argues, more sophisticated signaling models are needed, models which include signaling of resources rather than preferences, policy affecting the environment in which signals are sent, and exogenous changes in the environment affecting the informativeness of signals. These models are explored and are shown to be able to explain a number of phenomena the standard reputational model cannot.

\author{
Allan Drazen \\ Center for International Economics \\ 4118 Tydings Hall \\ University of Maryland \\ College Park, MD 20742 \\ and NBER \\ DRAZEN@ECON.UMD.EDU
}




\section{INTRODUCTION}

The effect of economic policies is rarely exactly what was planned or intended. One reason is uncertainty about how economic actors (including "nature") will behave and, hence, about how the economy will respond to policy. Such uncertainty means that policymakers cannot always predict the effect of their actions. Moreover, even when policymakers feel confident that they know the structure of the economy, surprises always happen, so much so that the occurrence of a surprise should be no surprise.

The divergence between the expected and the actual effect of policy is sometimes so great, however, that uncertainty alone cannot explain the difference. In the extreme, policies sometimes have the opposite effect from what was intended or from what might be expected Consider, for example, the effect of a liberalization of binding controls on outflow of capital. Simple economic theory suggests that if the controls are binding, lifting them should lead to an outflow of capital. The reality is often exactly the opposite -- when a country lifts binding controls on outflows, it experiences a capital inflow. ${ }^{1}$ The large number of cases in which an inflow was observed, as well as the magnitude of the inflows, suggests that something more than uncertainty is at work here.

The response of investors to displays of toughness in the attempt to defend a fixed exchange rate target provides another example in which the actual effects of policy are quite different from what simple logic might lead one to expect. Consider the case of the United Kingdom in 1992. In August and September, Prime Minister Major and Chancellor of the Exchequer Lamont vowed to defend the pound vigorously as speculative pressures mounted. Despite their tough statements, and the increases in short-term rates to back them up, reserves 
flowed out, with the Economist reporting that the Bank of England may have spent half of it reserves in a single day in its unsuccessful attempt to defend the pound.

Sweden's experience at the same time tells a similar story. With pressure against the Krona in September 1992, the Prime Minister and the Finance Minister both emphasized that they would defend the currency at any cost. Overnight interest rates were raised first to $24 \%$, then to $75 \%$, and finally to $500 \%$, but the Riksbank had to engage in massive borrowing to meet the demand for foreign exchange. Though the September crisis passed, in November there was renewed speculation against the Krona, with large capital outflows, followed by the Riksbank allowing the Krona to float. In short, in both the English and the Swedish cases, tough policy meant not simply to defend the exchange rate, but also to send the message that policymakers were firm in their commitment to the fixed exchange rate appeared to have the opposite effect. Here too, uncertainty about the effects of policy cannot explain the problem.

How can we explain the seemingly perverse effect of policy in these two cases? First of all, in each case, what really concerns investors is not so much current government policy, but the course of future policies. That is, in making their investment decisions, investors care about expected future returns and the effect that future government policy will have on these returns. Their behavior today is dictated by their expectation of what future policies will be, and they use all available information to try to forecast these policies. Hence, the main effect of current government policy on investment may be an indirect one, as investors use current government actions to try to infer what future actions may be. That is, they use current policies as an indicator or signal of future policies.

The argument that the primary effect of current policy may be due to the signal it sends 
about future policies is well known. When some characteristics of the policymaker are unknown (such as how committed a government is to a specific policy), current policy choices may reveal something about the policymaker's underlying preferences (his "type" as it has come to be known in this literature) and hence provide information about the likely course of future policies. For example, the use of "tough" policies to defend a fixed exchange rate can be thought of in terms of signaling: if the weight that the policymaker puts on defending the exchange rate relative to other policies is unknown, then by following a tough policy, the policymaker raises the probability that investors assign to the possibility that he is committed to the fixed parity at all costs and hence will not devalue in the future. That is, by not devaluing today, a government builds a reputation for toughness, and this reputation greatly affects investors' expectations.

In short, the standard model used in macroeconomics of using current policy to signal future policy relies on signaling of type and building a reputation, a reputation which leads observers to expect similar behavior in the future. There are several excellent surveys of reputational models in macroeconomics, and the arguments made are relevant in the openeconomy context. Among these are Rogoff (1987), Persson (1987), and Persson and Tabellini (1989). Hence, there is little payoff to presenting another survey of standard reputational arguments; in fact, there would be little point in examining the signaling role of economic policy if the models surveyed in these papers, based on simple reputational effects, were fully adequate in explaining the effects of signaling. To summarize, the basic result in a typical macroeconomic model of building a reputation via signaling is well represented by the result discussed in the previous paragraph on the effect of toughness in defending in defending the exchange rate -following a policy of not devaluing today increases the probability investors assign to no 
devaluation in the future; expectations of no devaluation in the future strengthens the currency today. In short, tough policy has the intuitive effect of strengthening a currency.

One is thus left with the feeling that a common view of the signaling effects of policies -namely, building a reputation for toughness (for example) via choice of tough policies -- fails to capture what is happening in many of the instances it is meant to explain. The apparently contrary effects of policies -- toughness in defending a fixed parity lowers, rather than raises confidence in the currency -- therefore argues for re-examining the signaling effects of government policy. Is it that current policy is read as giving no information about the future, that is, there is no signaling content? If there is a signal, is it grossly misread? Or, is the contrary effect of policy fully consistent with viewing current policy as a signal of future policy if one uses more sophisticated signaling models?

The purpose of this paper is to argue that signaling can explain incidents such as those discussed above, once one moves away from the simple reputational model of signaling of types. In the next section, I review the standard model of signaling of types and building a reputation. In section three, I show how the results may depend significantly on exactly what is being signaled. In the fourth section, I show how the basic result of the standard reputational model can be reversed when the environment in which the policy is chosen is taken into account, specifically, how current policy choices will affect the trade-offs the policymaker will face in the future. In section five, the role of exogenous changes in the environment is considered (in contrast to endogenous changes, as in section four). It is argued that the content of a signal, and, hence, the effect of policy, will be heavily influenced by changes in the environment. In the extreme, signals become uninformative. Section six concludes. 


\section{SIGNALING TOUGHNESS -- THE BASIC ARGUMENT}

I begin by reviewing the standard model of using policy to signal toughness. Some characteristic of the policymaker is not observed, so that current policy can be seen as possibly revealing or at least narrowing down his "type". Expectations of future policy are formed by forming expectations of the policymaker's type, since different types of policymakers follow different policies. That is, choice of policy may signal something about an important characteristic, which in turn indicates what future policy may be.

To make this idea more precise, one may think of an inference problem in forming expectations of a policymaker's future actions, where past observed actions lead one to expect future behavior of a given sort, that is, serve to build a reputation for future actions. As Fudenberg and Tirole (1991) put it, reputation is

the notion that a player who plays the same game repeatedly may try to develop a reputation for certain kinds of play. The idea is that if the player always plays in the same way, his opponents will come to expect him to play that way in the future and will adjust their own play accordingly. (p. 367)

The effect of signaling in terms of reputation may be illustrated by a simple variant of the standard Barro-Gordon (1983a, 1983b) model. The application is on the effect of toughness in defending the exchange rate, using a model in which surprise devaluations decrease unemployment, but expected devaluations have no effect. To enrich the basic Barro-Gordon model, assume there is a stochastic unemployment shock, so that the government's choice of policy will depend on the realization of the shock, as well as the cost it assigns to inflation relative to unemployment. To model policy conditional on the realization of shock, I will consider an "escape-clause" model. ${ }^{2}$ In a standard escape clause model the government chooses between 
following a no-devaluation rule and following a discretionary policy; in the latter case it optimally chooses the magnitude of devaluation as a function of the realized state of the world. ${ }^{3}$ For simplicity, assume instead that the choice is between the rule of a fixed parity, and the alternative of a devaluation of a fixed size. Formally, this is a state-contingent, two-part rule, so that devaluation at the pre-announced trigger could be characterized as carrying out the "announced," or at least implicit, policy. I think this view, though literally correct, misses the point -- that even a tough policymaker who plans ex ante to keep the fixed parity (and makes public statements to that effect) will devalue in adverse circumstances. I therefore take devaluation to represent departing from the announced (no-devaluation) policy.

Consider a small open economy producing a single good whose price is fixed in foreign currency terms at the world level. ${ }^{4}$ Suppose unanticipated devaluation reduces unemployment $u_{t}$ relative to unanticipated devaluation reduces unemployment $u_{t}$ relative to the natural rate $u_{N}$, where $u_{t}$ is also subject to a stochastic shock $\epsilon_{\mathrm{t}}$ :

$$
u_{t}=u_{N}-\sqrt{a}\left(e_{t}-\mathrm{E}_{\mathrm{t}-1} e_{t}\right)+\sqrt{a} \epsilon_{\mathrm{t}}
$$

where $e$ is the log exchange rate, E the expectation operator, and $a$ a constant representing the slope of the short-run tradeoff between unemployment and inflation.

The government's objective is to minimize an expected discounted loss function, where each period's loss is quadratic in the deviation of unemployment from a target level which is below the natural rate, $u_{\mathrm{N}}-\sqrt{a \kappa}$ ( $\kappa$ captures distortions leading to too high a natural rate), as well as in actual inflation. We assume there can be two types of governments, implying possible uncertainty about the government's objective function. 
The tough government (with superscript $T$ ) cares about inflation with a weight $\theta^{\mathrm{T}}$, while the weak government (superscript $W$ ) gives a lower weight $\theta^{\mathrm{w}}$ to inflation in its objective function. The I-type government's objective function conditioned on information available at $t=1$ is

$$
\begin{aligned}
\Lambda^{i} & =L_{1}^{i}+\beta E_{1} L_{2}^{i} \\
& =\left(u_{1}-u_{N}+\sqrt{a} \kappa\right)^{2}+\theta^{i}\left(e_{1}\right)^{2}+\beta E_{1}\left[\left(u_{2}-u_{N}+\sqrt{a} \kappa\right)^{2}+\theta^{i}\left(e_{2}\right)^{2}\right]
\end{aligned}
$$

Assume that wages are set before the shock $\epsilon_{\mathrm{t}}$ is observed. $\mathrm{E}_{1} \mathrm{e}_{2}$ is conditioned on information available at the end of the first period.

Asking what signal current policy sends about future policy is formally asking how the probability of a devaluation in the second period, denoted $\mu_{2}$, depends on the action of the government in the first period. With uncertainty about types, we may write $\mu_{2}$ as

$$
\mu_{2}(j)=p_{2}(j) \rho_{2}^{W}(j)+\left(1-p_{2}(j)\right) \rho_{2}^{T}(j)
$$

where $p_{2}$ is the probability the government is of type $w, \rho_{2}^{m}$ is the probability that a government of type $w$ will devalue (given the distribution of $\epsilon_{2}$ ), and $\rho_{2}^{T}$ is the probability that a government of type $T$ will devalue, and where $\mathrm{j}(=\mathrm{D}$ or $\mathrm{F})$ indicates whether the government devalued (D) or kept the exchange rate fixed $(\mathrm{F})$ in period 1.

To calculate $\rho_{2}^{i}$ one starts by solving the government's second period problem for given expectations of a devaluation $\mu_{2}(j)$, then substituting $\rho_{2}^{i}$ into (3) to solve for $\mu_{2}(j)$. The functional relation between policy choice and the realization of $\epsilon_{\mathrm{t}}$ will become clear from this calculation. The public is assumed to know the values $\theta^{\mathrm{T}}$ and $\theta^{\mathrm{w}}$, but does not observe the shock $\epsilon_{1}$. Denoting by $L_{2}^{i, D}(j)$ the single period loss function of a type I government if it devalues in the second period 
(where $\mathrm{j}$ is the first period action); then the government will devalue in period 2 if $\mathrm{L}_{2}^{\mathrm{i}, \mathrm{D}}(\mathrm{j})-\mathrm{L}_{2}^{\mathrm{i}, \mathrm{F}}(\mathrm{j})<$ 0 . This defines a critical value of the shock $\hat{\epsilon}_{2}^{i}(j)$

$$
\epsilon_{2}^{\prime}(j)=\frac{\left(a+\theta^{i}\right) s}{2 a}-\kappa-\mu_{2}(j) s
$$

where $s$ is the fixed devaluation size. The critical value is dependent both on the type of government (via $\theta^{i}$ ) and on previously observed policy $\left(\right.$ via $\left.\mu_{2}(j)\right)$. If the realization of $\epsilon_{2}$ is below this critical value $\hat{\epsilon}_{2}^{i}(j)$, a policy of maintaining the fixed parity is optimal; if it is above, a devaluation is optimal. When the distribution of $\epsilon$ is uniform between $-v$ and $+v$, we have (for an interior solution)

$$
\rho_{2}^{i}(j)=\operatorname{prob}\left(\epsilon_{2}>\hat{\epsilon}_{2}^{i}(j)\right)=\left(v-\hat{\epsilon}_{2}^{i}(j)\right) / 2 v
$$

To calculate the probability of government type, we assume that the public uses Bayesian updating. Expectations are conditioned on whether the government devalued or not in period 1, but not on the shock $\epsilon_{1}$, since the public does not observe it. If the public starts with uniform priors over the two types of governments, the probability that the government is weak conditional on its first period action may then be written

$$
p_{2}(\mathrm{D})=\frac{\rho_{1}^{W}}{\rho_{1}^{W}+\rho_{1}^{T}}, \quad p_{2}(\mathrm{~F})=\frac{1-\rho_{1}^{W}}{2-\rho_{1}^{W}-\rho_{1}^{T}}
$$

Note that $p_{2}(D)>p_{2}(F)$ as long as $\rho_{1}^{w}>\rho_{1}^{\mathrm{T}}$, that is, as long as the probability that a weak government devalues in the first period is greater than the probability that a tough government devalues. 
The probability that a given type would devalue in the first period is derived in an analogous way to the above calculation for $\rho_{2}^{i}$. We calculate a critical value of the shock in the first period, namely $\hat{\epsilon}_{1}^{\mathrm{i}}$, such that $\Lambda^{\mathrm{i}}(\mathrm{D})=\Lambda^{\mathrm{i}}(\mathrm{F})$. (The reader is referred to Drazen and Masson [1994] for the detailed calculation.) $\rho_{1}^{i}$, the probability that $\epsilon_{1}>\hat{\epsilon}_{1}^{i}$, can then be calculated, assuming the same uniform distribution as above.

To calculate $\mu_{2}(\mathrm{D})-\mu_{2}(\mathrm{~F})$, one combines equations (3), (5), and (6) to obtain, after some manipulation,

$$
\mu_{2}(D)-\mu_{2}(F)=\frac{1}{1-s / 2 v}\left[\frac{\left(\rho_{1}^{W}-\rho_{1}^{T}\right)\left(\theta^{T}-\theta^{W}\right) \frac{s}{4 a v}}{\left(\rho_{1}^{W}+\rho_{1}^{T}\right)\left(2-\rho_{1}^{W}-\rho_{1}^{T}\right)}\right],
$$

The term in brackets is unambiguously positive, meaning that observing a devaluation today increases the probability market participants assign to there being a devaluation tomorrow. (It is assumed that $1-\mathrm{s} / 2 \mathrm{v}>0$, for otherwise the devaluation size would exceed twice the maximum size of the shock it was aimed to offset).

Equations (6) and (7) represent the basic result of a standard model of a government signaling its commitment to fixed parities: observing a tough policy today (that is, no devaluation) when the policymaker's commitment to the fixed parity is uncertain leads the public to increase the probability it assigns to the government being of the "tough" type (equation (6)). This leads people to expect that the government is more likely to defend the fixed parity tomorrow, as it is more likely that the government is a tough type. One may then ask how signaling could yield the result that following a tough policy today makes people believe that devaluation is more likely tomorrow, rather than less likely? I will argue in section 4 below that the model in this section 
which considers only reputational effects misses a crucial factor in assessing the credibility of a commitment to fixed rates, namely the circumstances in which a government finds itself, and, specifically, the effect of today's policies on tomorrow's policy environment. In the next section, I want to consider how signaling could in fact lead to policy having apparently opposite effects to what might be naively anticipated even in a model of reputation as set out in this section. I will illustrate with in a model of the effects of liberalization of capital controls, addressing the empirical regularity set out in the introduction.

\section{SIGNALING RESOURCES RATHER THAN PREFERENCES}

In the standard model of building a reputation, playing tough makes people believe that future policymakers and hence future policy will be tough. Though casting the result in a signaling model with of asymmetric information about a policymaker's true preferences makes things rigorous, the basic result is intuitive. However, even in a model where only reputational

effects enter in, policy may have effects which seem counterintuitive. ${ }^{5}$ That is, policy choices may correctly communicate the policymaker's type, where "tough" governments are expected to follow and do in fact follow "tough" policies, but nonetheless the results appear quite different from what would naively expect.

The crucial point will be: What is the unobserved characteristic which the public tries to infer from observing a sequence of policy choices? In the model of the previous section, it is the policymaker's preferences over conflicting policy goals. Suppose instead the "characteristic" is the policymaker's resources, for example, foreign exchange reserves in a model of defending a fixed exchange rate. A "tough" policymaker might then be defined as one who has high foreign 
exchange reserves (or has the ability to borrow reserves). Having a high level of reserves allows more flexibility in choice of policies, for example, less of a need to raise interest rates to defend a fixed parity. Hence, when it is known that governments differ in an unobserved level of resources, but have the same preferences (that is, when their objectives are the same, but their "circumstances" differ), observing a "weak" policy may indicate that the policymaker has sufficient resources to withstand speculative attacks (i.e., is "tough"), while observing "tough" policy may signal underlying weakness.

This possibility can be illustrated by considering the effect of lifting of binding controls in financial markets. It would seem to be easy to predict the effect of lifting binding controls: funds should flow in the direction in which the constraint was binding. Take, for example, the removal of restrictions on capital outflows. If controls are binding when the liberalization is implemented (as indicated by offshore returns exceeding onshore returns), a liberalization should lead to a capital outflow, as funds flow to where returns are highest.

As indicated in the introduction, actual experience with lifting controls, however, is often quite different. Many countries that have removed controls on outflows have experienced rapid and massive inflows of capital. ${ }^{6}$ A frequently advanced explanation of this phenomenon, motivated by the work of Dooley and Isard (1980) and used more recently by Labán and Larrain (1993), runs as follows. Controls on outflows prevent investors from withdrawing capital from a country; the lifting of controls, by making it easier to take capital out in the future, will make investors more willing to bring capital in. Though the link between capital controls and reduced investment flexibility is an essential ingredient of any model of the effect of capital controls, this explanation is incomplete, for it depends crucially on the expectation that current policies will be 
continued into the future. But, government policies may change; in fact, a government that succeeds in attracting foreign investment would have a strong incentive to impose controls once capital has flowed in.

Bartolini and Drazen (1995) explain the observed inflows following liberalization of controls on outflows by viewing capital controls as potential signals of future government behavior. We consider a model in which investors have imperfect information about a government's intentions, and may therefore use the observation of current policies toward investment to infer the course of future policies. A regime of free capital mobility may signal that re-imposition of controls is less likely to occur in the future and, more generally, that future policies are likely to be more favorable to investment. If the signal is successful, capital flows in. In this section, I present a simplified version of the Bartolini-Drazen model, in which the motivation for capital controls is to widen the base for taxation of capital. Countries with poorly developed tax systems often rely heavily on revenues from financial repression, the difference between onshore and offshore real returns being enforced by regulations aimed at "trapping" capital onshore. The specifics of this version of the model are as follows. Consider a two-period model of a small open economy in which a single good $Y_{t}$ is domestically produced at time $t$ with onshore capital $K_{t}$, using a concave technology $Y_{t}=\mu_{t} K_{t}^{\beta}$, where $\mu_{t}$ is a stochastic productivity shock and $0<\beta<1$. The productivity shock $\mu_{t}$ takes a value $\bar{\mu}>0$ with probability $\pi$ and a value 0 with probability $1-\pi$. This country is assumed to be small in world markets, and to face a perfectly elastic supply of capital at the interest rate $r$.

Risk-neutral investors choose the stock of onshore capital $\mathrm{K}_{\mathrm{t}}$ to maximize total expected returns over the residual horizon, discounted by the factor $\rho=1 /(1+r)$. (The government's 
discount factor is also set at $\rho$.) It is assumed there are no capital flows for consumption smoothing, where this assumption is motivated by the apparent lack of empirical importance of this motive for capital flows. We thus focus on capital flows arising from investors' decisions on where to allocate their investment in response to domestic technology shocks, subject to endogenous policy constraints on capital mobility.

The government taxes capital wealth at the end of period two at a predetermined rate $\tau$, collecting revenues $\tau K_{2}$. Governments differ by the value they attach to this revenue, which may reflect different willingness to pursue revenues other than capital taxation. Alternatively, governments may differ in the importance they assign to capital mobility, a difference which cannot be signaled simply by announcement. These differences are parameterized by a variable $x$, where it is assumed that governments have better information on $x$ than investors. For concreteness, suppose $x$ represents revenues from sources other than capital taxation to which the government has access at the end of the period two. Let $x$ can take on three values: $x_{\mathrm{h}}, x_{\mathrm{m}}$, and $x_{1}$ $(=0)$, where $x_{\mathrm{h}}>x_{\mathrm{m}}>0$, and where investors assign prior probabilities of $q, p$, and 1-p-q respectively to these values. ${ }^{7}$ Government expenditure at the end of period two is $\tau K_{2}+x$, where the utility derived from government expenditure is represented by a utility function $W\left(\tau K_{2}+x\right)=$ $\ln \left(\tau K_{2}+x\right)$. Government utility from domestic capital is increasing in $\tau K_{t}+x$ (so that a potentially larger captive tax base tempts governments to impose controls), but at a decreasing rate (so that a larger $x$ reduces the incentives to trap a given outstanding stock of capital). Asymmetric information about the government's type $x$ is modeled by assuming that governments are informed of $x$ at the beginning of period one, whereas investors learn its value only at the beginning of period two. The cost of imposing controls is simply the cost to the government of 
breaking a commitment to free capital mobility: ${ }^{8}$ in each period in which controls are imposed, the government faces a cost $\xi>0$.

Before observing $\mu_{t}$, the government announces whether capital movements across borders are free or restricted in period $t$. If controls are imposed, the end-of-period stock of domestic capital, $K_{t}$, is constrained to be at least as large as the beginning-of-period stock, that is, $K_{t} \geq K_{t-1}$, with $K_{0}>0$. For shorthand, define a dummy variable $c_{t}$ to denote the regime of capital mobility prevailing in period $t$, letting $c_{t}=\mathrm{U}$ and $c_{t}=\mathrm{R}$ denote the cases of unrestricted and restricted capital mobility, respectively. After the government has announced its capital control policy, current-period productivity $\mu_{t}$ is revealed (either $\bar{\mu}$ or 0 ), and investors choose $K_{t}$, consistent with the prevailing financial regime. In the second period, taxes are collected.

The time structure of the model can be represented as in Table 1. The model is solved backwards, starting from the last (that is, second) period. With free capital mobility, investors, after observing $\mu_{2}$, choose onshore investment to equalize the marginal return from investing offshore (inclusive of principal), $1+r$, to that from investing onshore, $V_{2}=\mu_{2} \beta K_{2}^{\beta-1}+(1-\tau)$ (inclusive of the scrap value of a unit of capital). If $\mu_{2}=0$, onshore investment is zero. If $\mu_{2}=\bar{\mu}$, we have:

(8) $K_{2}^{*}\left(\mu_{2}\right) \equiv\left[\frac{\beta \bar{\mu}}{r+\tau}\right]^{\frac{1}{1-\beta}}$.

If, instead, capital controls are imposed in period two, the domestic stock of capital must satisfy the constraint $K_{2} \geq K_{1}$. 


\section{Table 1. Time structure of the model}

$t=0$

- Inherited stock of capital: $K_{0}$.

$t=1$

$-x$ is revealed to the government.

- Government chooses $c_{1} \in\{\mathrm{U}, \mathrm{R}\}$.

- $\mu_{1} \in\{0, \mu\}$ is realized and revealed.

- Public chooses $K_{1}$ (with $K_{1} \geq K_{0}$ if $c_{1}=\mathrm{R}$ ).

- Production takes place, profits are collected.

$t=2 \quad-x$ is revealed to the public.

- Government chooses $c_{2} \in\{\mathrm{U}, \mathrm{R}\}$.

$-\mu_{2} \in\{0, \mu\}$ is realized and revealed.

- Public chooses $K_{2}$ (with $K_{2} \geq K_{1}$ if $c_{2}=\mathrm{R}$ ).

- Production takes place, profits are collected, taxes are paid and transformed into public goods (together with $x$ ).

In the second period, the government must decide whether or not to impose controls at the beginning of the period, given the inherited stock $K_{1}$. The government's problem can be summarized by the function $\Psi_{2}=\Psi_{2}\left(K_{1}, x\right)$ that defines a type $x$ 's expected utility gain from imposing controls over not imposing controls at the beginning of period two, given $K_{1}$. Types 
for which $\Psi_{2}>0$ impose controls in this period, while the remaining types allow free capital mobility. $\Psi_{2}$ is defined as

$$
\Psi_{2}\left(K_{1}, x\right) \equiv \mathrm{E}_{2}\left[W\left(\tau K_{2}+x\right) \mid K_{1}, c_{2}=\mathrm{R}\right]-\xi-\mathrm{E}_{2}\left[W\left(\tau K_{2}+x\right) \mid K_{1}, c_{2}=\mathrm{U}\right]
$$

with expectations taken over $\mu_{2}$. When evaluating the gain from controls at the beginning of period two, the government does not know whether controls, if imposed, will be binding, which depends on the realization of $\mu_{2}$. To take an example, suppose $K_{1}<K_{2}(\bar{\mu})$, so that with probability $\pi$ controls will not be binding if imposed. $\Psi_{2}\left(K_{1}, x\right)$ will then take the form

$$
\Psi_{2}\left(K_{1}, x\right) \equiv(1-\pi)\left(\ln \left(\tau K_{1}+x^{i}\right)-\ln x^{i}\right)-\xi
$$

I will return to this equation when I consider specific parameter values.

Since the government's utility function $\Psi_{2}\left(K_{1}, x\right)$ decreases monotonically in $x$, there is a unique value of $x$, such that $\Psi_{2}\left(K_{1}, x\right)=0$. Governments with lower values of $x$ impose controls in period two, governments with higher values allow free capital mobility. Intuitively, capital controls raise expected tax revenues in period two, thereby increasing the government's expected utility from expenditure. The concavity of the government's welfare function, however, implies that this utility gain falls with $x$. For sufficiently large $x$, the gain from broadening the tax base is outweighed by the cost of imposing controls. One can further show that the function $\Psi_{2}$ is increasing in the existing stock of domestic capital: a higher $K_{1}$ provides a potentially larger tax base, and hence stronger temptation to trap capital onshore by imposing controls.

In period one, investors also compare the expected returns from investing onshore to the 
expected returns from investing offshore. In so doing, they must also consider the probability that capital controls may be imposed in period two. This probability depends on their current beliefs over government types, conditional on the policy chosen by the government at the beginning of period one. We denote the probability of controls in period two conditional on whether restricted or free mobility was observed in period one by $\gamma^{R}$ and $\gamma^{U}$ respectively, where the $\gamma^{c_{1}}$ depend on $K_{1}$. The $\gamma^{c_{1}}$ can then be used in calculating marginal returns to investing. The marginal return from investing offshore in period one equals $r+\rho(1+r)$ : in equilibrium, by going offshore in period one, investors can be assured of earning the risk-free rate in both periods. The expected marginal return from investing onshore in period one when $\mu_{1}=\bar{\mu}$, denoted $V_{1}$, is given by:

$$
V_{1}\left(K_{1} ; \gamma^{c_{1}}, \mu_{1}=\bar{\mu}\right) \equiv \bar{\mu} \beta K_{1}^{\beta-1}+\rho(1+r)\left[1-\gamma^{c_{1}}+\gamma^{c_{1}} \pi\right]+\rho \gamma^{c_{1}}(1-\pi)(1-\tau)
$$

(Of course, in the case where $\mu_{1}=0$, desired investment onshore is zero.) Desired period-one capital stock as a function of the observed policy can be found by equating $V_{1}$ and $r+\rho(1+r)$, to yield

$$
K_{1}^{c_{1}}=\left[\frac{\bar{\mu} \beta}{r+\rho \gamma^{c_{1}}(1-\pi)(r+\tau)}\right]^{\frac{1}{1-\beta}}
$$

for $c_{1}=\mathrm{R}, \mathrm{U}$. From (12) it is clear that the higher is $\gamma^{c_{1}}$, that is, the higher is the probability of controls in the second period, the lower will be the desired first-period capital stock. This is the key relationship underlying the signaling equilibrium: when the government decides whether or not to impose controls at the beginning of period one, it knows that an action leading to a more optimistic perception of its type, and hence a lower perceived probability of controls in period 
two, will induce a higher desired capital stock in period one.

To calculate the $\gamma^{c_{1}}$, investors use Bayes' Rule, starting with the prior probability that $c_{2}=$ $R$, and conditioning the posterior on the policy observed in period one. Let $R_{1}$ denote the set of types imposing controls in period one, $\mathrm{R}_{2}$ denote the set of types imposing controls in period two, $\mathrm{P}\left(\mathrm{R}_{1}\right)$ the prior probability of $c_{1}=\mathrm{R}, \mathrm{P}\left(\mathrm{R}_{2}\right)$ the prior probability of $c_{2}=\mathrm{R}$, and $\mathrm{P}\left(\mathrm{R}_{1} \cap \mathrm{R}_{2}\right)$ their joint probability. Then, by Bayes' rule, we have:

$$
\gamma^{\mathrm{R}} \equiv \operatorname{Pr}\left(c_{2}=\mathrm{R} \mid c_{1}=\mathrm{R}\right)=\operatorname{Pr}\left(c_{2}=\mathrm{R}\right) \cdot \frac{\operatorname{Pr}\left(c_{1}=\mathbf{R} \mid c_{2}=\mathrm{R}\right)}{\operatorname{Pr}\left(c_{1}=\mathrm{R}\right)}=\mathrm{P}\left(\mathrm{R}_{2}\right) \cdot \frac{\mathrm{P}\left(\mathbf{R}_{1} \cap \mathrm{R}_{2}\right)}{\operatorname{P}\left(\mathbf{R}_{1}\right) \cdot \mathrm{P}\left(\mathrm{R}_{2}\right)}
$$

Having established investors' policy as a function of the shock $\mu_{1}$ (either $\bar{\mu}$ or 0 ), the observed policy, and the associated probability $\gamma^{c_{1}}$, we can now solve, in implicit form, the government's problem. The problem of a government of type $x$ in period one is fully summarized by the function $\Psi_{1}\left(K_{0}, x\right)$ that defines the expected utility gain to a government of type $x$ from imposing controls in period one over not imposing controls, as a function of the existing capital stock. Types for whom $\Psi_{1}\left(K_{0}, x\right)>0$ will impose controls in period one, while types for whom $\psi_{1}\left(K_{0}, x\right) \leq 0$ will not.

An example will illustrate how removal of binding controls may lead to an expected capital inflow. Let $K_{0}=2.75, \bar{\mu}=1.5, \beta=.25, r=.05, \tau=.1, \pi=.15, p=.85, q=.1, \rho=.97, x_{h}=3$, $x_{m}=1.5, \xi=.1$. One can show that for these values, there exists a separating equilibrium in which $x_{\mathrm{h}}$ allows unrestricted capital mobility in both periods, type $x_{\mathrm{m}}$ allows unrestricted capital mobility in period one, but imposes controls in period two, and $x_{1}(=0)$ imposes controls in both periods. Moreover, in this equilibrium, a policy of unrestricted capital mobility causes an expected capital 
inflow (that is, $\left.\mathrm{E}_{1}\left[K_{1}^{*}\left(\mu_{1}, K_{0}, \mathrm{U}\right)\right]>K_{0}\right)$, even though the imposition of controls would lead to a desired outflow averaged across states (that is, $K_{0}>\mathrm{E}_{1}\left[K_{1}^{*}\left(\mu_{1}, K_{0}, \mathrm{R}\right)\right]$ ). Hence, a signaling model can explain why liberalization would lead to a capital inflow, even though controls would be binding if imposed.

\section{THE ROLE OF EXTERNAL CIRCUMSTANCES}

In the previous section we considered how reputational effects alone could lead to policy having a different effect than what a naive observer might expect. This leads to an even more basic question: Will reputational effects alone always be sufficient to explain the effect of signaling? Reputation-building via tough policy does not appear to explain the exchange rate experience of numerous countries; hence, one is lead to re-examine the basic arguments.

The essence of the reputational model of section two is that current policy signals type and a policymaker's type determines what he will do, so that tough policy signals that the policymaker is tough, and therefore will follow tough policies in the future. But, in reality, things are not quite so simple. Whether or not an announced policy is carried out reflects more than the policymaker's intentions. It will also depend on the situation in which he finds himself. Even the "toughest" policymaker cannot ignore the cost of very high unemployment; he may renege on a no devaluation pledge in sufficiently adverse circumstances, that is, in times of weak economic activity, when pressures to restore high employment are strong. ${ }^{9}$ Hence, when tough policymakers are not infinitely tough, the credibility the public assigns to an announced policy should therefore reflect not only the characteristics of the policymaker, but the economic 
environment as well. In the previous section, in defining type in terms of a policymaker's resources, I took a first look at the role that constraints will play in the signals that policy sends. In this section, I want to investigate the role of constraints and environment much more fully.

Taking account of the environment in which the policymaker chooses whether or not to devalue has a number of important implications. In terms of reputation, the most obvious is that reneging on a no devaluation pledge need not harm reputation. If a policymaker devalues when external circumstances are known to be especially adverse, then this action will not reveal that he will devalue in more normal times. Therefore, devaluing under extreme circumstances need not lessen the credibility of a commitment to a fixed parity. To put the point another way, the signaling content of inflating will be low when circumstances are such that it is known that all types would inflate, and vice-versa. I will pursue this in section 5 below.

Less obviously, the converse is not true: not devaluing in adverse circumstances need not enhance credibility, as the basic reputational model suggests. That is, maintaining a fixed parity when times are bad may actually lower the credibility of an announced commitment to no devaluation. It is here that distinguishing between the reputation of the policymaker and the credibility of the policy become so important. In most cases, not devaluing when times are bad will enhance the reputation of the policymaker, in the sense of increasing the probability that he puts a high weight on the cost of inflation. However, the public knows that his devaluation decision tomorrow will depend on the circumstances in which he will find himself as well as on his preferences. Tough policy could lower the credibility of an commitment to fixed exchange rates at the same it strengthens the policymaker's reputation, if tough policy today is seen as significantly worsening the trade-off he will face tomorrow. 
In a non-stochastic setting, it is now well known that policy choices today may constrain the environment tomorrow in such a way that current policy has seemingly counterintuitive effects. This is the essence of the argument first made by Sargent and Wallace in their now classic article, "Unpleasant Monetarist Arithmetic" (1981). Reducing growth of the money supply today will reduce seigniorage today (assuming the economy is on the "right" side of the seigniorage Laffer curve) which, if no other fiscal changes are made, will require the government to raise additional revenues at some point in the future to meet their intertemporal budget constraint. If the higher revenue needs tomorrow are met by increasing money growth tomorrow, then investors will take a cut in money growth today as indicating an increase in money growth tomorrow. With forward-looking expectations, higher expected money growth tomorrow will positively affect expected and thus actual inflation today. Sargent and Wallace pointed out that this expectational effect may be so strong that a cut in the rate of monetary growth today induces an increase, rather than a fall, in today's inflation rate. ${ }^{10}$ There is no signaling in the sense used above in the Sargent and Wallace model (or in the models mentioned in footnote 9), since there is full information about the policymaker's characteristics. But the basic effect is there: "tight" monetary policy can have the opposite effect from what one would naively expect due to today's policy affecting the trade-off the policymaker faces tomorrow.

The persistence of the effects in policy could be put in a signaling model of the type set out in section two by having asymmetric information about a policymaker's characteristics. Such a model was considered by Drazen and Masson (1994) to study how the signaling content of current policy, and hence its credibility, would be affected. Whereas the persistence of policy in Sargent and Wallace comes via the government's intertemporal budget constraint, in Drazen and 
Masson it comes from the characterization of unemployment. To model persistence simply in the Barro-Gordon model of a trade-off between unemployment and surprise devaluations of section 2, suppose that the second period unemployment rate depends on the deviation of first period unemployment from the natural rate. That is, equation (1) could be written:

$$
u_{2}=u_{N}-\sqrt{a}\left[\left(e_{2}-E_{1} e_{2}\right)-\delta\left(u_{1}-u_{N}\right)\right]+\sqrt{a} \epsilon_{t}
$$

where $\delta \geq 0$ is a measure of persistence in unemployment fluctuations. The critical value of the shock $\hat{\epsilon}_{2}^{\mathrm{i}}(\mathrm{j})$ becomes

$$
\hat{\epsilon}_{2}^{l}(j)=\frac{\left(a+\theta^{i}\right) s}{2 a}-\kappa-\mu_{2}(j) s-\delta\left(u_{1}-u_{N}\right)
$$

Solving as in the case of no persistence, one can obtain an expression, analogous to (7), for the difference between the probability of period two devaluation if devaluation was observed in period one and this probability if fixed rates were observed in period one ${ }^{11}$ :

$$
\mu_{2}(D)-\mu_{2}(F)=\frac{1}{1-s / 2 v}\left[-\frac{\sqrt{a} \delta s}{2 v}+\frac{\left(\rho_{1}^{W}-\rho_{1}^{T}\right)\left(\theta^{T}-\theta^{W}\right) \frac{s}{4 a v}}{\left(\rho_{1}^{W}+\rho_{1}^{T}\right)\left(2-\rho_{1}^{W}-\rho_{1}^{T}\right)}\right]
$$

Though this expression looks simply like (7) with another term added in, the persistence parameter $\delta$ will affect both terms inside the brackets. The effect on $\rho_{i}^{i}(I=T, W)$ arises because the critical level $\hat{\epsilon}_{\mathrm{l}}^{\mathrm{i}}$ of the first period shock depends on welfare in both periods and hence on $\delta$. When $\delta>0$, the dependence of $\mu_{2}(D)-\mu_{2}(F)$ on $\delta$ is complicated, reflecting the contribution of both terms. One can show, however (see Drazen and Masson (1994) for details) that for $\delta$ sufficiently large, the persistence effect will tend to dominate the signaling effect and (16) will 
become negative.

To summarize, positive persistence of unemployment implies that no devaluation in the first period may raise, rather than lower, the public's expectation of a devaluation in the second period. Shocks that are not offset through a devaluation in period 1 have further unfavorable effects in period 2 , increasing the probability that a government of either type will devalue. If these persistence effects are sufficiently strong ( $\delta$ large), not devaluing in the first period will raise the probability of a devaluation in the second. Thus, credibility will not necessarily be enhanced by "playing tough" in period one.

\section{EXOGENOUS EXTERNAL CIRCUMSTANCES AND UNINFORMATIVE SIGNALS}

In the previous section, we considered how evolution of the policymaker's environment that is endogenous to his actions could radically change the signal that tough policy sent. Today's choices affect tomorrow's environment in such a way that playing tough may lower the credibility of a tough policy.

A different sort of issue arises when the some exogenous and known characteristic of the environment affects policy choices. Consider the example of devaluation. As indicated above, if a policymaker devalues when external circumstances are known to be especially adverse, then this action will not reveal that he will devalue in more normal times. That is, if the environment is such that any type of government, no matter how tough, would devalue, then devaluation conveys no information about type. Conversely, maintaining fixed rates when external circumstances are so favorable that even the weakest government would maintain fixed rates conveys no information. In short, external circumstances may imply that the signaling content of a given 
policy is low or non-existent.

This point may be seen in a variant of the model of capital inflows and capital controls in section 3. Consider that model in which a government of unknown type decides whether or not to impose controls in the current period as a function of the existing capital stock and expected capital flows resulting from its policy choice, but where the world interest rate $r$ can vary over time. Specifically, suppose the world interest rate $r_{t}$ is stochastic, drawn each period from an unchanging distribution $\mathrm{M}(r)$. Suppose further that all current period variables are known to the government when it makes its current period decision on capital controls. (For simplicity, assume the productivity parameter $\mu_{t}$ is a known constant, say at $\mu>0$.) The lower is the world interest rate $r_{t}$ the higher will be capital inflow into the country. Hence, for a low enough interest rate, all types may choose a policy of unrestricted capital mobility in a given period. Analogously, for a high enough world interest rate, all types would impose controls. In each of these cases, current policy would be uninformative. Thus, if liberalization in response to an external favorable shock is widespread, the policy has quite different effects than if one country liberalizes.

Bartolini and Drazen (1996) model this possibility more formally in a multi-period variant of the model of section 3, where $x$ is interpreted as the cost of reneging on a commitment to unrestricted capital mobility, where this cost is incurred the first time controls are imposed. (The one-time nature of the cost implies that once a government imposes controls, it will keep controls in place forever after. This set-up is dictated by tractability.) We concentrate on the evolution of information about government types over time as a function of the evolution of the exogenous world interest rate. In each period, the set of possible types depends on both the history of observed policies and the history of interest rates. Current policy will be informative for some 
histories, uninformative for others.

Specifically, there is a continuum of possible types $x$, where $x$ is initially distributed between 0 and $\infty$. As policy choices are observed, investors refine the set of possible types. This refinement works as follows. The government's optimal policy in period $t$ is summarized by a cutoff type $\hat{x}_{t}=\hat{x}_{t}\left(K_{t-1}, r_{t}\right)$ who is indifferent between not imposing controls and imposing controls, conditional on not having previously imposed controls, and not imposing controls. Governments with $x<\hat{x}_{t}$ impose controls, those with $x \geq \hat{x}_{t}$ allow free mobility of capital, unless they have previously imposed controls. The set of possible types in period one, for example, after policy has been observed is no longer $[0, \infty]$, but is $\left[\hat{x}_{1}\left(K_{0}, r_{1}\right), \infty\right]$ if a policy of no controls has been observed, since it is known that $x \geq \hat{x}_{1}$ in this case. In period two, the cut-off level is $\hat{x}_{2}\left(K_{1}, r_{2}\right)$. If $\hat{x}_{2} \leq \hat{x}_{1}$, then no 'possible' government would impose controls in period two. Policy choice is uninformative and investors do not refine their information set. If $\hat{x}_{2} \geq \hat{x}_{1}$, then imposition of controls implies that $\hat{x}_{1}<x<\hat{x}_{2}$, while no controls implies $x \geq \hat{x}_{2}$. And so on. Once controls are observed, there is no more updating of information. Unlike standard signaling models, the external environment, here the history of world interest rates, plays a crucial role in this updating. The dependence of the informativeness of policy choice on the history of the external environment can be quite important. Consider possible capital flows to a number of countries where current policy is taken as an indicator of future policy (call these "emerging markets"). Let us define by $\hat{r}_{t}$ the interest rate at which the lowest possible type at time $t$ is indifferent between 
imposing and not imposing controls, given the inherited stock $K_{t-1}$ and the policy history. For $r_{t} \leq \hat{r}_{t}$, no government that had not previously imposed controls would impose controls, so that the policy observed in period $t$ does not help investors refine their knowledge of government types and, hence, their forecast of future returns to investment. Suppose in period $t$ (the present) the world interest rate is sufficiently low to spur a large inflow of capital into all emerging markets, thereby supporting a policy of widespread free capital mobility (i.e., $r_{t}<\hat{r}_{t}$ ). In this period, investors have the opportunity to allocate capital for maximum returns in period $t+1$ and onward (the future), in light of events observed up to period $t-1$ (the past). If the past interest rate was low (i.e., $r_{t-1}<\hat{r}_{t-1}$ ), then all countries allow free capital mobility at both $t-1$ and $t$, and (since all countries are identical a priori) receive the same flow of investment at $t$, despite the underlying-but unobservable--dissimilarity in $x$ and in the likelihood of future capital controls: all-round liberalization at $t-1$ has destroyed the information content of the observed policy. If the future interest rate, $r_{t+1}$, is high, there is a desired outflow of capital from all emerging markets, but countries whose government assigns a relatively low cost to abandoning free capital mobility impose controls on outflows, and investors are "trapped" in these countries, earning a low rate of return. If, instead, the period $t-1$ interest rate, $r_{t-1}$, had exceeded $\hat{r}_{t-1}$ (for the same interest rates at $t$ and $t+1$ ), investors could have refined their prior information over government types, and would have invested less at $t$ in those countries which were more likely to have controls at $t+1$. That is, investors have increased ability at $t$ to prevent inefficient capital allocation in period $t+1$, allowing them to allocate less capital to low $x$ countries and more capital to high $x$ countries than 
when $r_{t-1}<\hat{r}_{t-1}$. (This argument is worked out in detail in Bartolini and Drazen [1996]).

\section{CONCLUSIONS}

The purpose of this paper has been to show how signaling models can be useful in understanding why the effects of policy may be quite different, in fact often opposite to what might be naively expected. On the one hand, it should probably be no surprise that when the primary effect of current policy on economic behavior is via the information it conveys about future policy, complicated effects are possible. On the other hand, standard applications of signaling models in open-economy macroeconomics may leave the impression that signaling has intuitive effects, whereby "tough" policy today sends the clear signal that policy will be "tough" tomorrow, so that the effect of toughness is straightforward. The effect of toughness is not at all straightforward, as I hope this paper has demonstrated. 


\section{References}

Barro, Robert J., and David B. Gordon (1983a), "Rules, Discretion, and Reputation in a Model of Monetary Policy," Journal of Monetary Economics, vol. 12, pp. 101-21.

(1983b) "A Positive Theory of Monetary Policy in a Natural Rate Model," Journal of Political Economy, vol. 91 , pp. 589-610.

Bartolini, Leonardo, and Allan Drazen (1995), "Capital Account Liberalization as a Signal," mimeo, University of Maryland.

(1995b), "When Liberalization Reflects External Shocks, What Do We Learn?," mimeo, University of Maryland.

Blanchard, Olivier J. (1985), "Credibility, Disinflation, and Gradualism," Economics Letters, vol. 17, pp. 211-17.

Dooley, M.P., and P. Isard (1980), "Capital Controls, Political Risk, and Deviations from Interest-Rate Parity," Journal of Political Economy, vol. 88, 370 - 84.

Drazen, A. (1985), "Tight Money and Inflation: Further Results " Journal of Monetary Economics, vol. 15, pp. $113-20$.

and E. Helpman (1990), "Inflationary Consequences of Uncertain Macroeconomic Policy", Review of Economic Studies, vol. 57, pp. 147-66.

and P. Masson (1994), "Credibility of Policies versus Credibility of Policymakers", Quarterly Journal of Economics, vol. 109, pp. 735 - 54.

Flood, Robert P. (1983), "Comment on Buiter and Miller," in Frenkel, J., ed., Exchange Rates and International Macroeconomics (Chicago: University of Chicago Press), pp. $359-65$.

, and Peter Isard (1989), "Monetary Policy Strategies," IMF Staff Papers, vol. 36, pp. $612-32$.

Fudenberg, D., and J. Tirole (1991), Game Theory, MIT Press: Cambridge, MA.

Giavazzi, F., and L. Spaventa (1990), "The 'New' EMS," CEPR Discussion Paper No. 369.

Labán, R., and F. Larraín (1993), "Can a Liberalization of Capital Outflows Increase Net Capital Inflows?," Universidad Catolica de Chile, Working Paper No. 155. 
Liviatan, Nissan (1984), "Tight Money and Inflation," Journal of Monetary Economics, vol. 13, pp. 5 - 15 .

Lohmann, Susanne (1990), "Monetary Policy Strategies--A Correction," IMF Staff Papers, vol. 37 , pp. $440-45$.

Mathieson, D., and L. Rojas-Suarez (1993), Liberalization of the Current Account, Occasional Paper No. 103, IMF, Washington.

Obstfeld, Maurice (1991), "Destabilizing Effects of Exchange Rate Escape Clauses," NBER Working Paper No. 3603 (January).

Persson, Torsten (1988), "Credibility of Macroeconomic Policy: An Introduction and Broad Survey," European Economic Review, vol. 32, pp. 519-32. and Guido Tabellini (1989), Macroeconomic Policy, Credibility and Politics, Harwood: London.

Rogoff, K. (1987), "Reputational Constraints on Monetary Policy," Carnegie-Rochester Conference Series on Public Policy vol. 26, pp. 141 - 81.

Sargent, Thomas and Neil Wallace (1981), "Some Unpleasant Monetarist Arithmetic," Federal Reserve Bank of Minneapolis Quarterly Review, vol. 5, p. 1 - 17. 


\section{Notes}

1. Italy liberalized controls on outflows in the mid 1980 's, with a several-fold rise in inflows after the main liberalization measures were adopted; New Zealand effectively abolished longstanding exchange and capital controls in November 1984, with a resultant tripling to quadrupling of inflows; Uruguay liberalized in the mid 1970's, and private capital inflows moved from a deficit of $\$ 4$ million in 1974 , to surpluses of $\$ 140$ million in 1976 and $\$ 360$ million in 1978; Spain liberalized in the second half of the 1980s, after which private capital inflows (net of FDI) surged. (Data, from IMF Financial Statistics, are summarized in Bartolini and Drazen [1995]).

2. Escape clause models are used by Flood and Isard [1989], Lohmann [1990], and Obstfeld [1991].

3. The policymaker is modeled as choosing between a rule and discretion on the basis of the realized state of the world, rather than a complex state-contingent rule where the action associated with every contingency is specified ex ante. This approach is meant to capture the notion that all states of the world cannot be foreseen, so that a fully state-contingent rule cannot be specified. To avoid the problem that a policymaker would always choose discretion ex post, it is assumed that the policymaker must pay a private fixed cost when choosing discretion.

4. This model is taken from Drazen and Masson (1994).

5. As indicated above, in section 4 , it will be argued that there are other effects which could lead to the belief that the tougher policy is today, the weaker it will be tomorrow.

6. Giavazzi and Spaventa (1990), Mathieson and Rojas-Suarez (1993), and Bartolini and Drazen (1995), among others, review a number of such episodes.

7. Bartolini and Drazen (1995) consider a continuum of types, which makes the model significantly more complicated.

8. See for instance, Rogoff (1987), where the cost of breaking a no-inflation commitment is modeled as independent of the inflation rate itself, and Barro (1986), where a government's cost is zero for zero inflation and prohibitive for positive inflation.

9. Flood [1983] and Blanchard [1985] make a related point: current policymakers will be replaced if policies are too tough, leading to an easing of policies.

10. See also Liviatan (1984) and Drazen (1985) for a more general discussion of this possibility, and Drazen and Helpman (1990) for a more general analysis of the effect of expectations of future policy on current macroeconomic dynamics.

11. See Drazen and Masson (1994) for the calculations. 